\title{
Participation in Urban Development: A Civil Society Initiative-a Case Study of Udon Thani, Thailand
}

\author{
Thanadorn Phuttharak ${ }^{1} \&$ Apisak Dhiravisit ${ }^{2}$ \\ ${ }^{1}$ Development Science, Faculty of Humanities and Social Sciences, Khonkaen University, Thailand \\ ${ }^{2}$ Program in Faculty of Humanities and Social Sciences, KhonKaen University, Thailand \\ Correspondence: Thanadorn Phuttharak, Development Science, Faculty of Humanities and Social Sciences, \\ Khonkaen University, Thailand. E-mail: thanadorn4245@gmail.com
}

Received: September 26, $2014 \quad$ Accepted: December 11, $2014 \quad$ Online Published: January 14, 2015
$\begin{aligned} & \text { doi:10.5539/ass.v11n4p206 } \\ & \text { URL: http://dx.doi.org/10.5539/ass.v11n4p206 }\end{aligned}$

\begin{abstract}
This paper aimed to examine the influenced of civil society participation in urban development. A quantitative approach was adopted in the study. A questionnaire was used in the study to collect data from four hundred participants, who were Udon Thani citizens, and the sample was selected by quota sampling and purposive sampling. Descriptive analysis and multiple logistic regressions were used to analyze the data. The results found that factors that influenced the civil participation in urban development were health, political issues, and perceptions on urban development.
\end{abstract}

Keywords: civil society, participation, urban development, Udon Thani

\section{Introduction}

Urbanization and the growth of the modern city has been considered as an economic change based on capitalism, and is an important issue that needs to be considered urgently, particularly in developing countries in Southeast Asia, including Thailand. The National Economic and Social Development Plan, which was developed based on the Western development approach, resulted in a major change in the economic and social system in Thailand. The economic system has turned from an agricultural system into an industrial system, which focused on export-oriented production. The change also affected both rural and urban areas. The migration of workers increased from rural areas into urban areas or industrial areas (Suthiprapa et al., 2008). The city's infrastructure could not support such a huge number of worker migrations anymore. This pattern then was called over-urbanization (Thavinpipatkul, 2008)

Decentralization was introduced decades ago, and the government applied this concept to distribute the development in regional areas. The growth poles theory has been applied to develop the secondary urban centers that function as a pole of economic growth. Although the policy is quite effective in an attempt to distribute the development to regional areas, the policy led to the creation of a new issue, the sustainability of a regional city, which included rural parts of a secondary city (Glassman \& Sneddon, 2003). The problem also reflected the inability of the state to impose regulations about city sustainability. Another problem was that the scope of the administrative division of the city could not cover the complexity of the city system. There were many limitations on administrative boundaries and local authority on city planning, the development policy, and the city problem resolution approach; these limitations resulted in inefficient city development.

Yang (2010) describes a policy on sustainable urban development that was composed of 5 perspectives: 1) the responsibility of the polluter for the future, 2) the balance of environmental responsibility, economic performance, and social solidarity, 3) the integration of the sustainable development approach, which focused on all parties of the city, 4) the promotion of city development participation to city stakeholders, and 5) sustainable development based on the participation of the local government, private sector, and civil society. Yang also suggested that sustainable urban development was responsible for the obligations of all parties. The parties had to participate in city development processes with fairness and creativity.

Building cities for the people, with the people: Public participation in planning and designing urban infrastructure and services is essential for identifying what, why, and how change should occur. Participation of all stakeholders in a particular city ensures that any action taken and services provided are accurate reflections of 
the needs of people and that the benefits of development are shared more equally. Well-managed participation can bring out concerns of different stakeholder groups, such as women, youth, older people, and people with disabilities; participation can also deal with conflicting development objectives. Furthermore, it is a method by which all available options can be explored (UN-Habitat, 2012).

According to previous findings and reviews of the urbanization phenomenon in Thailand, the researcher has attempted to reveal the issue of urbanization in the regional city of Thailand, which has been growing with a high rate of development. The article is going to explain factors that influenced the participation of stakeholders in the city development. In addition, the article specifies the participation of a civil society in the city development, as this was the group that related to the city development directly. Findings of the study will contribute to policy issuing and development planning for the rapid growth city in Thailand and other cities in Asia.

\section{Objective}

The objective is to examine the influence of civil society participation on urban development of Udon Thani, Thailand.

\section{Theoretical Framework}

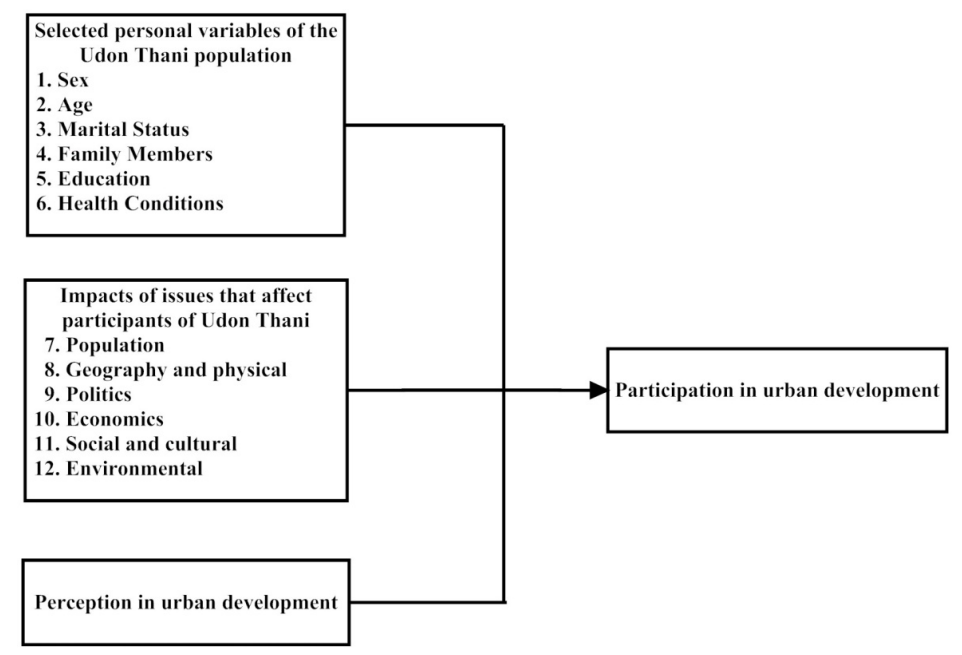

Figure 1.

The theoretical framework shows independent factors that lead to the participation of the public sector in urban development. Independent factors include 1) the personal variables of the Udon Thani population, including sex, age, marital status, family members, education, and health conditions; 2) impacts that affect the Udon Thani population, which include population, geography and physical, politics, economic, social and cultural, and environmental factors; and 3) the perception of the public sector regarding urban development. These variables would influence the participation of the public sector in urban development.

\section{Methodology}

\subsection{Research Participants}

A total of four hundred participants from the Udon Thani Municipality and eight local municipalities around the Udon Thani Municipality were employed in this study. Participants were selected using quota sampling and purposive sampling from the population of the Udon Thani Municipality.

\subsection{Research Design}

This study was a quantitative study in which responses of research participants were collected using the questionnaire method. A descriptive statistic and regression design was adopted in the study. The regression design was adopted for the researcher to test the individual and combine the influences of the independent variables on the dependent variable.

\subsection{Measures}

The questionnaire was used in the study. The questionnaire contained four parts, which were: 1) personal characteristics of participants, 2) impact of urban development, 3) perception of participants on urban development, and 4) participation of participants on urban development. The Likert scale was adopted in the 
questionnaire and divided into five items, which were none, strongly disagree, disagree, agree, and strongly disagree.

\subsection{Procedure}

Four hundred copies of the questionnaire were given to research participants to personally complete, having sought and obtained their consent to participate in the study. The completed copies of the questionnaire were later retrieved from respondents for analysis. Four hundred copies were available for use in the data analysis.

\section{Results}

Table 1. Selected personal variables of the Udon Thani population

\begin{tabular}{|c|c|}
\hline Variables & Frequency $(\%)$ \\
\hline \multicolumn{2}{|l|}{ 1) $\mathrm{Sex}$} \\
\hline$>$ Male & 43.3 \\
\hline$>$ Female & 56.8 \\
\hline \multicolumn{2}{|l|}{ 2) Age } \\
\hline$>11-27$ & 17.8 \\
\hline$>28-48$ & 39.0 \\
\hline$>49-66$ & 29.8 \\
\hline$>$ Over 67 & 13.5 \\
\hline \multicolumn{2}{|l|}{ Marital Status } \\
\hline$>$ Single & 28.5 \\
\hline$>$ Married & 61.0 \\
\hline$>$ Separated & 3.0 \\
\hline$>$ Divorced & 2.0 \\
\hline$>$ Widow & 5.5 \\
\hline \multicolumn{2}{|l|}{ 4) Family Members } \\
\hline$>1$ & 4.3 \\
\hline$>2-4$ & 59.3 \\
\hline$>5-8$ & 35.8 \\
\hline$>9-12$ & 0.8 \\
\hline \multicolumn{2}{|l|}{ 5) Education } \\
\hline >Primary School & 44.8 \\
\hline$>$ Secondary School & 19.3 \\
\hline >Vocational & 21.0 \\
\hline >Higher Degree & 15.0 \\
\hline \multicolumn{2}{|l|}{ 6) Health Condition } \\
\hline >Allergy & 20.7 \\
\hline$>$ Cancer & 4.7 \\
\hline$>$ Muscle and Bone Disease & 18.8 \\
\hline$>$ Digestion Disease & 5.2 \\
\hline$>$ Dental Disease & 9.7 \\
\hline$>$ Obey & 4.3 \\
\hline$>$ Stress & 4.7 \\
\hline$>$ Other & 27.2 \\
\hline$>$ Non-Disease & 4.7 \\
\hline
\end{tabular}

A descriptive analysis was done to show the frequency distribution and percentage of some selected personal characteristics variables. The results from Table 1 showed that most of the participants were female (56.8 percent), while 43.3 percent were males. Most of the participants' ages were between 28 and 48 years old (39.0 percent). For marital status, 61.0 percent of participants were married. The number of family members was typically between 2 and 4 persons (59.3 percent). Most of the participants graduated from primary school at 44.8 
percent. Regarding their health conditions, most of the participants had other diseases that were not on the list (27.2 percent), and the next were allergies and muscle and bone diseases (20.7 percent and 18.8 percent, respectively).

Table 2. Impacts of issues that affect participants of Udon Thani

\begin{tabular}{lll}
\hline Impact Issues & Level of Impact & Frequency \\
\hline > Population & Medium & 43.0 \\
$>$ Geography and physics & Medium & 56.0 \\
>Politics & Low & 47.5 \\
$>$ Economics & Medium & 68.0 \\
>Social and culture & Medium & 44.3 \\
> Environment & Medium & 53.8 \\
\hline
\end{tabular}

Table 2 showed the summary of impacts that affect the participants of Udon Thani. The results from Table 2 showed that the impacts of urban development on this population are represented at a medium level (43.0 percent). The impact of urban development on geography and physics was at a medium level (56.0 percent), while impact on politics was at low level (47.5 percent). The impact of urban development on economics was at a medium level (68.0 percent), the impact on social and culture was at a medium level (44.3 percent), and the impact of urban development on the environment was at a medium level (53.8 percent).

Table 3. Perception of participants in the urban development of Udon Thani

\begin{tabular}{ll}
\hline Level of Perception & Frequency \\
\hline Low (Score 5-11) & 39.3 \\
Medium (Score 12-18) & 45.3 \\
High (Score 19-25) & 15.5 \\
Total & $100.0(400)$ \\
Mean $=13.0 ;$ S.D. $=4.9 ;$ Max $=25 ;$ Min $=5$ & \\
\hline
\end{tabular}

Table 3 showed the summary of the perception of participants regarding the urban development of Udon Thani. The results from Table 3 showed that the perception of participants on the urban development of Udon Thani was represented at a medium level (45.3 percent). It was found that participants perceived on development plant supporting city expansion the most, followed with traffic congestion resolution and social development plan respectively.

Table 4. Participation of participants in the urban development of Udon Thani

\begin{tabular}{ll}
\hline Level of Participation & Frequency \\
\hline Low (Score 6-13) & 34.5 \\
Medium (Score 14-22) & 57.5 \\
High (Score 23-30) & 8.0 \\
Total & $100.0(400)$ \\
Mean = 15.7; S.D. $=5.2 ;$ Max $=30 ;$ Min $=6$ & \\
\hline
\end{tabular}

Table 4 showed the summary of the participation of participants regarding the urban development of Udon Thani. The results from Table 3 showed that the participation of participants regarding the urban development of Udon Thani was represented at a medium level (57.5 percent). However, participation on cooperation with government agencies was still at low level, so it was necessary to find the suitable approach to work with government agencies for strengthening public participation. 
Table 5. Regression analysis showing factors that influence civil participation in the urban development of Udon Thani

\begin{tabular}{llll}
\hline Variables & b & Beta & Sig. \\
\hline Health & 2.922 & 0.128 & 0.002 \\
Political & 0.346 & 0.241 & 0.000 \\
Perception of urban development & 0.473 & 0.449 & 0.000 \\
Constant $=6.4974$ & & &
\end{tabular}

R Square $=0.424 ; \mathrm{F}=15.602 ;$ Sig. of $\mathrm{F}=0.000 ; \mathrm{N}=336$

Table 5 showed the summary of a regression analysis showing the factors that influence civil participation in the urban development of Udon Thani. The results from Table 5 showed that there are significant influences on health on civil participation $(b=2.922$, Beta $=0.128)$ and significant influences of political factors on civil participation $(b=0.346$, Beta $=0.241)$. Similarly, there is a significant influence of the perception of urban development on civil participation $(b=0.473$, Beta $=0.449)$, and the 5 percent of significance level.

\section{Conclusion and Discussion}

Based on an analysis of this population, the researcher found that the level of public opinion was at a medium level. The influence of civil participation on urban development caused an increasing number of citizens in the Udon Thani Municipality and the surrounding community. In addition, the migration of foreign workers was another factor that influenced the municipality's urban development. It could be concluded that the change of the population, including worker migration and cross-national marriages, would affect civil participation in urban development.

In an analysis of the geography and physical factors, the researcher found that the level of public opinion was at a medium level. Of the factors, traffic congestion around the city of Udon Thani affected to UdonThani citizen the most. Next were the waste problem and drainage system, respectively. This could reflect that Udon Thani citizens were aware of the problems that might impact their living situations. This resulted in the fact that the citizens wanted to participate in urban development with government agencies.

Regarding politics, the researcher found that the level of public opinion was at a low level. Political issues lead to investments in public infrastructure development and to supporting city expansion in the future, such as the constructions of roads, electricity, water supply, and drainage system. Government agencies should cooperate with the public sector to determine problem resolutions together. This will increase the public awareness on urban development and let the public sector monitor the work of the government (Kaewhawong, 2001).

An examination of the economic factors found that the level of public opinion was at a medium level. Family expenses, family debts, and economic difference between families were factors related to participation in urban development. It could be said that the economic status of people related directly to urban development-that is, those who had economic problems would give less priority to urban development than those who were of a higher economic status.

An examination of the social and cultural factors found that the level of public opinion was at a medium level. Most of the participants focused on social problem resolutions, such as issues with gambling and drugs. In addition, the relationship and harmony of the community and the issue of crime were also worrisome. Inequality within a community caused conflict in the community. Therefore, it is important to prioritize the family to take care of people for better life in the future.

An examination of the environmental factors found that the level of public opinion was at a medium level. Most of the participants focused on noise pollution, waste disposal, and general pollution. These factors directly affected the well-being of the people's daily lives and could have caused health and mental problems for people. The result was supported by Thongyou's study (2014) in terms of environmental concerns due to rapid urbanization, which is now expanding to suburban areas. Although pollution was generated within urban areas, people in suburban areas are ones who cannot avoid being affected. This issue should be a priority for cities with rapid growth, particularly because of the importance of creating a sustainable city.

An analysis of the perception of the civil society in urban development found that the level of perception was at a medium level. Most of the civil perception issues related to traffic congestion and social development planning, such as citizens' protection against crime and drugs. This could be explained that people paid attention 
to the city's expansion plan, which was created by a government agency, because those factors directly affected people's lives.

The participation of a civil society in urban development found that the level of participation was at a medium level. Most of the civil participation issues related to participation in religion and culture in the community, community security, and environmental management. Although this was participation within the community, participation approach could encourage people to develop a sense of cherishing the community and encourage them to contribute to the issues of policy development.

\section{Research Recommendations}

According to the research results, certain guidelines were recommended to encourage the participation of the public sector in urban development: 1) it is essential to acknowledge the importance of participation in urban development to civil stakeholders who live in the area because this type of stakeholder is directly affected by urban development. Thus, civil participation is very important to guide urban planning, and it also reflects the government's efficiency in urban development. 2) Sharing information should be done to receive more participation from the public sector. In the past, many development policies were issued without the public sector's awareness, which resulted in practical disadvantages to public sector and related stakeholders in the policy issuing. Therefore, the process of promoting participation among the public sector should be conducted and applied as a flagship of urban development to empower the public sector in urban development policy; ultimately, this will allow officials to achieve the goal of creating a sustainable city.

In addition, an in-depth study should be conducted to reveal the deeply qualitative data about the influential variables in this study and examine their roles to create a guideline, allowing the city to issue the best policy for urban development based on participation from the public sector.

\section{Acknowledgements}

This research paper is funded through the National Research University (NRU) Grant from Khon Kaen University. Thank you to all of those on the educational committee in the doctor of philosophy program in development science, Faculty of Humanities and Social Sciences, Khon Kaen University, Research Group on Wellbeing and Sustainable Development (WeSD) for their helpful advice. Thank you to the government and private sectors in Udon Thani and particularly to the Udon Thani International Cooperation and Development office (UDICAD) for the data provided for this project.

\section{References}

Abbott, J. (1996). Sharing the City: Community Participation in Urban Management. London: Earthscan Publications Limited.

Childe, V. G. (1950). The Urban Revolution. The Town Planning Review, 21(1), 3-17.

Dijk, M. P. (2006). Managing Cities in Developing Countries: The Theory and Practice of Urban Management. Cheltenham: Edward Elgar Publishing.

Dowall, D. E., \& Clarke, G. (1966). A Framework for Reforming Urban Land Policies in Developing Countries. Washington, D.C.: The International Bank for Reconstruction and Development, the World Bank.

Flyvbjerg, B. (1996). The Dark Side of Planning: Rationality and Realrationalität. In S. Mandelbaum, L. Mazza, \& R. Burchell (Eds.), Explorations in Planning Theory (pp. 383-394). New Brunswick, NJ: Center for Urban Policy Research Press.

Friedmann, J. (1986). The World City Hypothesis. Development and Change (Vol. 17, pp. 69-83). London, Beverly Hills and New Delhi: SAGE. http://dx.doi.org/10.1111/j.1467-7660.1986.tb00231.x

Frumkin, H., Frank, L., \& Jackson, R. (2004). Urban sprawl and public health: Designing, planning, and building for healthy communities. Washington: Island Press.

Gantsho, M. S. V. (2008). Cities as Growth Poles Implications for Rural Development. A Paper Presented at the Annual Meetings Seminar of Infrastructure, Private Sector, Regional Integration \& Trade, held in Maputo, Mozambique.

Glassman, J., \& Sneddon, C. (2003). Chiang Mai and Khon Kaen as Growth Poles: Regional Industrial Development in Thailand and Its Implications for Urban Sustainability. Annals of the American Academy of Political and Social Science, Rethinking Sustainable Development, 590, 93-115. http://dx.doi.org/10.1177/ 0002716203257075

Haemyuratham, A. (1985). History of interior UdonThani province. Bangkok: Amarin Printing. 
Hopkins, L. D. (2001). Urban Development: The Logic of Making Plans. Washington: Island Press.

Jone, G. W. (2002). Southeast Asia Urbanization and the Growth of Mega-Urban Regions. Journal of Population Research, 19(2).

Kuvinpanth, P. (2002). Urban Sociology and Urban Anthropology. Bangkok: Chulalongkorn Press.

Naipinit et al. (2013). Local Community Participation in the Conserve Candle Festival, a Case Study of Ubon Ratchathani Province, Thailand. Asian Social Science, 9(13), 282-288. http://dx.doi.org/10.5539/ass.v9n13 p282

Noh, A. (2008). Remaking Public Participation: The Case of Singapore. Asian Social Science, 4(7), 19-32.

Omar, D. B., \& Leh, O. L. H. (2009). Malaysian Development Planning System: Kuala Lumpur Structure Plan and Public Participation. Asian Social Science, 5(3), 30-36. http://dx.doi.org/10.5539/ass.v5n3p30

Prompakping et al. (2013). The Land-use Changes and Social Vulnerability of Udon Thani City. Khon Kaen Research Group on Wellbeing and Sustainable Development Khon Kaen University.

Rimmer, P. J., \& Dick, H. (2009). The city in Southeast Asia: Pattern, processes, and policy. Singapore: National University of Singapore Press.

Suthiprapa, J., Mithranon, P., Watana, P., \& Taesrikul, C. (2008). Bangkok-globalising the city of angels. In G. W. Jones, \& M. Douglass (Eds.), Mega-urban regions in Pacific Asia: Urban dynamics in a global era. Singapore: National University of Singapore Press.

Thavinpipatkul, D. (2008). Urbanization and social change in developing countries. Bangkok: Chulalongkorn University Press.

Thongyou et al. (2014). Perceptions on Urbanization Impact on the Hinterlands: A Study of Khon Kaen City, Thailand. Asian Social Science, 10(11), 33-41. http://dx.doi.org/10.5539/ass.v10n11p33

UNHABITAT. (2012). Sustainable Urbanization in Asia: A Sourcebook for Local Governments. Nairobi: UNON, Publishing Services Section.

Wheeler, S. M., \& Beatley, T. (2009). The Sustainable Urban Development Reader (2nd ed.). Abingdon: Routledge.

Yang, Y. (2010). Sustainable Urban Transformation Driving Forces, Indicators and Processes. Zurich: ETH Zurich.

\section{Copyrights}

Copyright for this article is retained by the author(s), with first publication rights granted to the journal.

This is an open-access article distributed under the terms and conditions of the Creative Commons Attribution license (http://creativecommons.org/licenses/by/3.0/). 